\title{
Does preoperative carotid stenosis screening reduce perioperative stroke in patients undergoing coronary artery bypass grafting?
}

\author{
Khalil Masabni, MD, ${ }^{\mathrm{a}}$ Sajjad Raza, MD, ${ }^{\mathrm{a}}$ Eugene H. Blackstone, MD, ${ }^{\mathrm{a}, \mathrm{b}}$ Heather L. Gornik, MD, ${ }^{\mathrm{c}}$ and \\ Joseph F. Sabik III, MD
}

\begin{abstract}
A number of institutions routinely perform carotid artery ultrasound screening before coronary artery bypass grafting $(\mathrm{CABG})$ to identify carotid artery disease requiring revascularization before or during $\mathrm{CABG}$, with the expectation of reducing perioperative neurologic events. The assumptions are that carotid disease is causally related to perioperative stroke and that prophylactic carotid revascularization decreases the risk of post-CABG neurologic events. Although carotid artery stenosis is a known risk factor for perioperative stroke in patients undergoing $\mathrm{CABG}$, it might be a surrogate marker for diffuse atherosclerotic disease rather than a direct etiologic factor. Moreover, the benefit of prophylactic carotid revascularization in patients with asymptomatic unilateral carotid disease is uncertain. Therefore, we have reviewed the literature for evidence that preoperative carotid artery screening, by identifying patients with significant carotid artery stenosis and altering their management, reduces perioperative neurologic events in those undergoing CABG. (J Thorac Cardiovasc Surg 2015;149:1253-60)
\end{abstract}

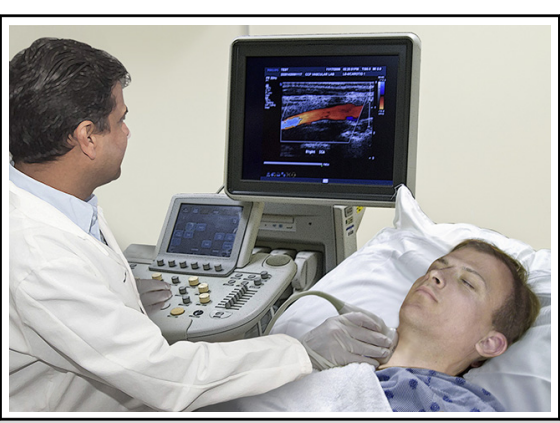

Carotid artery duplex ultrasound.

\section{Central Message}

A number of institutions routinely perform carotid artery ultrasound screening before coronary artery bypass grafting, with the expectation of decreasing perioperative neurologic events. However, carotid artery stenosis might simply be a surrogate marker for diffuse atherosclerotic disease, and the benefit of prophylactic carotid revascularization in asymptomatic patients with unilateral carotid disease is uncertain.

\begin{abstract}
Author's Perspective
A number of institutions routinely perform carotic artery ultrasound screening before coronary artery bypass grafting $(\mathrm{CABG})$ to identify carotid artery disease that necessitates revascularization before or during $\mathrm{CABG}$, with the expectation of reducing perioperative neurologic events. However, among patients undergoing $\mathrm{CABG}$, clinical variables alone can identify those who have significant carotid artery disease, with as high a degree of sensitivity as ultrasound. Moreover, carotid duplex ultrasound screening, whether selective or nonselective, identifies only a minority of patients who will develop perioperative stroke, and intervening for those with carotid disease might not decrease the risk of these neurologic events.
\end{abstract}

From the Department of Thoracic and Cardiovascular Surgery, ${ }^{\mathrm{a}}$ Heart and Vascular Institute; Department of Quantitative Health Sciences, ${ }^{\mathrm{b}}$ Research Institute; and Department of Vascular Medicine, ${ }^{\mathrm{c}}$ Heart and Vascular Institute, Cleveland Clinic, Cleveland, Ohio.

This study was supported in part by the Sheikh Hamdan bin Rashid Al Maktoum Distinguished Chair in Thoracic and Cardiovascular Surgery, held by Dr Sabik, and the Kenneth Gee and Paula Shaw, PhD, Chair in Heart Research, held by $\mathrm{Dr}$ Blackstone. These individuals played no role in the collection of data or analysis and interpretation of the data, and had no right to approve or disapprove publication of the finished article.
Received for publication Sept 18, 2014; revisions received Jan 29, 2015; accepted for publication Feb 3, 2015; available ahead of print March 24, 2015.

Address for reprints: Joseph F. Sabik III, MD, Department of Thoracic and Cardiovascular Surgery, Cleveland Clinic, 9500 Euclid Ave/Desk J4-1, Cleveland, OH 44195 (E-mail: sabikj@ccf.org).

0022-5223/\$36.00

Copyright (C) 2015 by The American Association for Thoracic Surgery http://dx.doi.org/10.1016/j.jtcvs.2015.02.003 


\section{Abbreviation and Acronym \\ $\mathrm{CABG}=$ coronary artery bypass grafting}

Stroke is a devastating complication of coronary artery bypass grafting (CABG). ${ }^{1}$ For this reason, a number of institutions routinely screen patients undergoing $\mathrm{CABG}$ $(\text { Table } 1)^{2-7}$ for severe carotid artery stenosis and potential carotid revascularization, with the expectation of reducing the risk of post-CABG stroke. This practice is contrary to guidelines recommending screening in selected patients only. ${ }^{8,9}$ The underlying assumptions are that carotid disease is causally related to perioperative stroke and that prophylactic carotid revascularization decreases its risk. However, if carotid artery stenosis is not a direct etiologic risk factor for perioperative stroke, routine nonselective screening may not be cost effective. ${ }^{4,10}$ In addition, the benefit of prophylactic carotid revascularization in patients with asymptomatic unilateral carotid disease is controversial. ${ }^{11-15}$ Therefore, we have reviewed the literature for evidence that preoperative carotid artery screening, by identifying patients with substantial carotid stenosis and altering their management, decreases perioperative neurologic events in patients undergoing CABG.

\section{PERIOPERATIVE STROKE IN PATIENTS UNDERGOING CABG}

Stroke is a serious complication of $\mathrm{CABG}$ that occurs in $1.3 \%$ to $2.0 \%$ of patients ${ }^{1,16-18}$ and results in acute mortality of up to $38 \% .^{19,20}$ The cause of post-CABG stroke is multifactorial, but because most strokes occur $\geq 24$ hours after surgery, embolic events are the most likely culprits. ${ }^{15,21-24}$ Macroembolization of atherothrombotic debris from the severely atherosclerotic aorta is strongly associated with postoperative stroke. ${ }^{16,25-27}$ Shedding of emboli to the brain might be caused by manipulation of the ascending aorta during aortic clamping, cannulation, and proximal graft anastomosis. ${ }^{23,28,29}$ Dislodging of emboli from the heart due to manipulation by the surgeon or atrial fibrillation are other possible causes. ${ }^{30}$ Intraoperative hemodynamic abnormalities, such as hypotension during cardiopulmonary bypass, and pulmonary diastolic hypertension after cardiopulmonary bypass, are also associated with increased risk of post-CABG stroke. ${ }^{31}$ Microembolization of platelet aggregates and turbulent blood flow during cardiopulmonary bypass are other possible causes. ${ }^{28,32}$ In addition, atherosclerotic disease of the cerebral arteries is an important mechanism of stroke in patients undergoing $\mathrm{CABG}^{7}$
Risk factors for perioperative stroke include older age, prior stroke or transient ischemic attack, peripheral artery disease, hypertension, left ventricular dysfunction, preoperative atrial fibrillation, ${ }^{1,25,28,33-36}$ and carotid artery stenosis. ${ }^{11,24,28,34,37}$ A carotid bruit has been found to be a preoperative predictor of severe aortic arch atheroma. ${ }^{38}$ Therefore, some consider carotid artery disease to be an epiphenomenon, serving as a marker for diffuse systemic atherosclerotic disease, rather than being a causal factor. ${ }^{10,12,39,40}$ Data from Cleveland Clinic patients undergoing noncardiac surgery demonstrated no association between carotid artery stenosis and stroke (odds ratio 1.0, with a $95 \%$ confidence interval of 0.99-1.02) for a 10-unit increase in internal carotid artery peak systolic velocity, the variable used to quantify carotid artery stenosis. $^{41}$

\section{POSSIBLE MECHANISMS BY WHICH CAROTID ARTERY STENOSIS COULD LEAD TO PERIOPERATIVE STROKE}

It is thought that carotid intraplaque hemorrhage can result in plaque destabilization ${ }^{42-46}$ and intimal ulceration, creating a nidus for thromboembolism. ${ }^{47-52}$ Intraplaque hemorrhage detected by magnetic resonance imaging is associated with increased risk of ipsilateral stroke in symptomatic and asymptomatic nonsurgical patients ${ }^{53,54}$ and is strongly related to onset of symptoms. ${ }^{55} \mathrm{We}$ hypothesize that anticoagulating patients during $\mathrm{CABG}$ might be responsible for increased intraoperative risk of intraplaque hemorrhage. Mechanical causes can trigger intraplaque hemorrhage as well, such as turbulent blood flow and hypertension, both of which can occur during cardiac surgery. ${ }^{55}$

Impaired cerebral hemodynamic function distal to carotid artery stenosis is another determinant of postoperative stroke. ${ }^{22,56}$ Maximally dilated vessels distal to carotid artery stenosis can no longer vasodilate in response to hemodynamic compromise. Therefore, perioperative reduction in blood pressure or cardiac output in this group of patients is hypothesized to lead to cerebral ischemia. ${ }^{40,56}$ Moreover, reduced cerebral blood flow might result in decreased washout of microemboli in patients undergoing $\mathrm{CABG} .^{57}$

\section{DETECTING CAROTID ARTERY DISEASE}

Carotid artery duplex ultrasound, which is used to visualize plaque and measure flow velocity to quantify stenosis, is the screening test usually used to identify patients with carotid artery stenosis (see Central Image). ${ }^{58}$ The sensitivity of carotid ultrasound to detect carotid artery stenosis, of $>70 \%$ is $86 \%$ to $90 \%$, with a specificity of $87 \%$ to $94 \%$. ${ }^{59}$ Although ultrasound screening is currently used to determine the degree of carotid artery stenosis, other duplex-determined plaque characteristics are also 
TABLE 1. Carotid artery screening in patients undergoing coronary artery bypass grafting

\begin{tabular}{|c|c|c|c|c|c|c|}
\hline First author and year & $\begin{array}{c}\text { No. of } \\
\text { screened patients }\end{array}$ & Population & $\begin{array}{c}\text { Routine } \\
\text { screening }\end{array}$ & $\begin{array}{l}\text { Screening } \\
\text { method }\end{array}$ & $\begin{array}{c}\text { Degree of internal } \\
\text { carotid artery stenosis } \\
\text { considered significant }(\%)\end{array}$ & Prevalence $(\%)$ \\
\hline Wanamaker $^{104} 2012$ & 559 & CABG & No & DUS & $>50$ & 36 \\
\hline Ansari $^{81} 2011$ & 116 & $\begin{array}{l}\text { CABG with/without } \\
\text { valve surgery }\end{array}$ & No & DUS & $>70$ & 6.6 \\
\hline Drohomirecka $^{80} 2010$ & 682 & CABG & No & DUS & $\geq 50$ & 18 \\
\hline Cornily $^{82} 2010$ & 205 & CABG & No & DUS & $\geq 70$ & 5.8 \\
\hline Anastasiadis ${ }^{4} 2009$ & 307 & Cardiac surgery & Yes & DUS & $>70$ & 6.5 \\
\hline Kiernan $^{79} 2009$ & 643 & CABG & No & DUS & $>70$ & 7.7 \\
\hline Sheiman $^{77} 2007$ & 295 & CABG & Yes & DUS & $\geq 50$ & 24 \\
\hline Shirani $^{6} 2006$ & 1045 & $\begin{array}{l}\text { CABG with/without } \\
\text { valve surgery }\end{array}$ & Yes & DUS & $>60$ & 6.9 \\
\hline Durand $^{5} 2004$ & 1138 & CABG & Yes & $\begin{array}{l}\text { DUS and/or } \\
\text { angiography }\end{array}$ & $\geq 70$ & 13.4 \\
\hline Fukuda $^{3} 2000$ & 308 & CABG & Yes & DUS & $>50$ & 14.3 \\
\hline Salasidis $^{78} 1995$ & 387 & CABG & No & DUS & $>80$ & 8.5 \\
\hline
\end{tabular}

$C A B G$, Coronary artery bypass grafting; $D U S$, duplex ultrasonography.

associated with cerebrovascular symptoms, including hypoechoic lesions (low grayscale median, larger juxtaluminal black area), plaque heterogeneity (presence of noncalcified, discrete white areas without acoustic shadowing), plaque ulceration, and larger plaque area. ${ }^{60-75}$ Therefore, both carotid artery flow velocity and plaque characterization could be used to identify patients who are at higher risk of developing perioperative neurologic events when undergoing CABG.

Regardless of whether carotid artery stenosis is an etiologic factor for perioperative stroke, carotid artery ultrasound screening detects only a minority of patients who experience perioperative neurologic events. For example, by screening every patient undergoing CABG, Durand and colleagues ${ }^{5}$ found that $13.4 \%$ had carotid artery stenosis of $\geq 70 \%$. Among those who developed postoperative stroke after undergoing CABG, only $19 \%$ had carotid artery stenosis of $\geq 70 \%$ ipsilateral to the side of the stroke.

An alternative to routine ultrasound screening is risk profiling. Several groups have identified risk factors associated with significant carotid artery stenosis in patients undergoing CABG (Table 2). Peripheral artery disease, cerebrovascular disease (prior stroke or transient ischemic attack), and old age were the risk factors most consistently identified in these studies. ${ }^{2-4,6,37,76-81}$ Applying carotid disease-screening algorithms to cohorts of ultrasoundscreened patients undergoing CABG showed that most who had significant carotid artery stenosis could be detected. $^{5,77,82}$ Thus, Durand and colleagues ${ }^{5}$ found that a risk-profiling algorithm based on a prior stroke or transient ischemic attack, carotid bruit on exam, or age $>65$ years would have missed significant carotid disease in only $2.3 \%$ of patients undergoing CABG (26 of 1138), although this represented $17 \%$ of 152 patients with significant carotid disease, and 582 had a false-positive result. ${ }^{5}$ Thus, their selective screening algorithm had a sensitivity and specificity of $83 \%$ and $41 \%$, respectively.

Sheiman and colleagues ${ }^{77}$ used 7 risk factors (history of carotid artery disease, prior cerebrovascular event, hypertension, diabetes, peripheral artery disease, smoking, left main coronary disease, and female gender) to predict which patients have carotid artery disease. The presence of any 1 of these factors was $100 \%$ sensitive, but only $30 \%$ specific, in detecting patients with $\geq 50 \%$ carotid stenosis. Similarly, Cornily and colleagues ${ }^{82}$ found that risk factors including age $>70$ years, history of cerebrovascular disease, diabetes mellitus, peripheral artery disease, or carotid bruit on physical examination could have detected 11 of 12 patients with significant carotid artery stenosis. These studies suggest that clinical factors are sensitive in identifying patients with carotid disease, but that specificity is low, requiring more specific screening modalities, such as ultrasound, in more than half of patients.

\section{ROLE OF CAROTID REVASCULARIZATION IN DECREASING THE RISK OF NEUROLOGIC EVENTS}

Carotid revascularization by staged or synchronous carotid endarterectomy or carotid artery stenting is considered acceptable in patients with symptomatic carotid disease, bilateral $70 \%$ to $99 \%$ carotid stenosis, or a unilateral $70 \%$ to $99 \%$ carotid stenosis with a contralateral occlusion. ${ }^{10,83-85}$ However, most carotid revascularization procedures are performed prophylactically in patients with asymptomatic unilateral carotid artery stenosis, ${ }^{11,19,20,24,37}$ and the value of such interventions is uncertain. 
TABLE 2. Risk factors for significant carotid artery stenosis

\begin{tabular}{|c|c|c|c|c|c|c|c|c|c|c|}
\hline First author and year & Older age (y) & Female & Bruit & Smoking & DM & Htn & LMCA & $\begin{array}{l}\text { History } \\
\text { of CVD }\end{array}$ & PAD & Others \\
\hline Wanamaker $^{104} 2012$ & Yes & Yes & NS & No & No & Yes & Yes & Yes & Yes & Renal failure (dialysis) \\
\hline Ansari $^{81} 2011$ & Yes & NS & NS & No & No & No & NS & Yes & Yes & $\begin{array}{l}\text { Hypercholesterolemia/abnormal } \\
\text { renal function }\end{array}$ \\
\hline Cornily $^{82} 2010$ & NS & No & Yes & No & Yes & No & NS & No & Yes & \\
\hline Drohomirecka $^{80} 2010$ & Yes & No & NS & NS & No & No & No & Yes & Yes & Unstable angina \\
\hline Anastasiadis ${ }^{4} 2009$ & No & No & Yes & No & No & No & No & Yes & NS & \\
\hline Kiernan $^{79} 2009$ & NS & NS & Yes & NS & NS & NS & Yes & Yes & Yes & \\
\hline Sheiman ${ }^{77} 2007$ & NS & No & NS & Yes & Yes & Yes & Yes & Yes & Yes & History of carotid disease \\
\hline Shirani $^{6} 2006$ & $>50$ & Yes & NS & No & Yes & NS & NS & NS & NS & $\begin{array}{l}\text { Cholesterol }>240 \\
\text { Triglycerides }>240\end{array}$ \\
\hline Durand $^{5} 2004$ & $>65$ & Yes & Yes & NS & No & Yes & Yes & Yes & Yes & \\
\hline Fukuda $^{3} 2000$ & No & NS & NS & No & No & No & No & Yes & Yes & Atherosclerosis of ascending aorta \\
\hline D’Agostino $^{37} 1996$ & Yes & Yes & NS & Yes & Yes & NS & Yes & Yes & Yes & Prior vascular operation \\
\hline Salasidis $^{78} 1995$ & Yes & NS & NS & No & No & No & NS & Yes & Yes & Prior carotid endarterectomy \\
\hline Berens $^{76} 1992$ & NS & Yes & NS & Yes & NS & No & Yes & Yes & Yes & \\
\hline
\end{tabular}

The assumed benefit of treating asymptomatic patients is extrapolated from the Asymptomatic Carotid Atherosclerosis Study and Asymptomatic Carotid Surgery Trial, which concluded that carotid endarterectomy decreases the 5-year risk of ipsilateral stroke in patients with asymptomatic isolated carotid disease. ${ }^{86,87}$ However, the purpose of prophylactic carotid revascularization in patients undergoing $\mathrm{CABG}$ is to reduce perioperative neurologic events. Thus, long-term risk reduction of stroke should not be used as a justification to perform carotid revascularization in these patients, especially if operative morbidity from the combined procedures is higher than the added risks of the procedures performed separately. ${ }^{12}$ Results of the ongoing Coronary Artery Bypass graft surgery in patients with Asymptomatic Carotid Stenosis (CABACS) randomized clinical trial comparing the safety and efficacy of isolated CABG versus synchronous $\mathrm{CABG}$ and carotid endarterectomy in patients with asymptomatic high-grade carotid artery stenosis will elucidate whether surgical carotid revascularization helps to reduce the risk of perioperative stroke in patients undergoing $\mathrm{CABG} .{ }^{88}$ However, the trial does not have a staged carotid artery stenting arm, so the best approach to managing these patients might remain unclear. $^{89}$

Currently, several findings argue against the usefulness of carotid revascularization in patients undergoing CABG. First, no direct causal relationship has been found between carotid artery stenosis and postoperative ipsilateral stroke, ${ }^{12}$ and most strokes occur outside the territory supplied by the carotid artery.$^{90}$ Second, the risk of perioperative stroke in patients with carotid disease is low. ${ }^{12,13,91-93}$ In a meta-analysis by Naylor and Bown, ${ }^{94}$ the risk of ipsilateral stroke in patients with a unilateral, asymptomatic $50 \%$ to $99 \%$ stenosis was found to be only $2 \%$.

Third, if carotid disease is truly an important risk factor for post-CABG stroke, then patients with bilateral, severe carotid disease undergoing unilateral carotid revascularization should have a high rate of stroke ipsilateral to the "nonrevascularized" artery. However, studies show that the risk of perioperative neurologic events ipsilateral to the nonrevascularized artery is low. ${ }^{94,95}$ Fourth, combined CABG and carotid revascularization is associated with higher risk than isolated CABG. Thus, Ghosh and colleagues ${ }^{13}$ found that occurrence of death, cerebrovascular events, and myocardial infarction within 30 days of $\mathrm{CABG}$ without prophylactic revascularization in asymptomatic patients with carotid artery stenosis of $\geq 70 \%$ was $4 \%$, but Naylor ${ }^{10}$ reported that the composite risk of death, stroke, or myocardial infarction within 30 days of combined CABG and carotid revascularization was $9 \%$ to $11 \%$.

Surgeons can consider several other strategies to reduce the risk of perioperative neurologic events. First, monitoring of blood pressure throughout the procedure and postoperatively; avoiding extremes of blood pressure during surgery is important, because both hypertension, when it leads to carotid artery plaque rupture, and hypotension, when it leads to cerebral ischemia, can initiate neurologic damage. Second, postoperative antiplatelet therapy should be considered, ${ }^{8,96}$ because most strokes result from thromboembolic events.

Third, because these patients are likely to have aortic arch atheroma as part of their diffuse atherosclerotic disease, intraoperative assessment of the aorta should be done before clamping, and strategies should be used to 
decrease the shedding of emboli from the aorta during surgery, such as off-pump CABG without a partial occlusion clamp, or on-pump CABG with continuous perfusion without aortic clamping. Monitoring brain oxygen saturation during CABG through cerebral oximetry, to avoid profound cerebral desaturation, is also associated with better outcomes. ${ }^{97}$ Moreover, dynamic bubble trap and arterial line filters may be considered to reduce the occurrence of stroke in patients undergoing $\mathrm{CABG}{ }^{98,99}$

\section{VALUE OF ROUTINE CAROTID SCREENING}

The Society of Thoracic Surgeons and the American College of Cardiology/American Heart Association recommend ultrasound screening for carotid artery stenosis in selected patients only (class IIa recommendation, level of evidence C). ${ }^{8,9,100}$ The guidelines document ${ }^{11}$ "2012 Appropriate Use Criteria for Peripheral Vascular Ultrasound and Physiological Testing" rated all clinical scenarios for cerebrovascular duplex scanning before cardiac surgery as uncertain (or "may be appropriate"). ${ }^{101}$ The Society of Vascular and Interventional Neurology recommends screening of selected patients undergoing CABG (grade B), but screening of all patients was considered a grade $\mathrm{D}$ recommendation. ${ }^{102}$

Because carotid artery stenosis is common in patients with coronary artery disease and is a marker of increased risk of cardiovascular events, detecting it is thought by some to be important for preoperative risk stratification. ${ }^{103}$ However, the cost effectiveness of such nonselective screening in patients undergoing cardiac surgery is unknown. Indeed, the first research priority identified by the writing committee of the "2012 Appropriate Use Criteria for Peripheral Vascular Ultrasound and Physiologic Testing" document was to determine the clinical and cost effectiveness of carotid screening in patients undergoing cardiac surgery. ${ }^{101}$

\section{CONCLUSIONS}

Among patients undergoing $\mathrm{CABG}$, clinical variables alone can identify those who have significant carotid artery disease with as high a degree of sensitivity as ultrasound. However, low specificity would seem to dictate ultrasound screening, and possibly additional confirmatory testing ${ }^{4}$ of a large proportion of these patients, to alleviate a false-positive diagnosis. On the other hand, carotid duplex ultrasound screening, whether selective or nonselective, identifies only a minority of patients who will develop perioperative stroke, and intervening for those with carotid disease might not decrease the risk of these neurologic events. Absence of a direct causal relationship between carotid artery stenosis and ipsilateral stroke, and the increased morbidity associated with carotid revascularization, support the argument that prophylactic carotid revascularization might be of no benefit in asymptomatic patients undergoing CABG. This area, then, is clearly in great need of further research.

\section{Conflict of Interest Statement}

Authors have nothing to disclose with regard to commercial support.

\section{References}

1. Tarakji KG, Sabik JF III, Bhudia SK, Batizy LH, Blackstone EH. Temporal onset, risk factors, and outcomes associated with stroke after coronary artery bypass grafting. JAMA. 2011;305:381-90.

2. Salehiomran A, Shirani S, Karimi A, Ahmadi H, Marzban M, Movahedi N, et al. Screening of carotid artery stenosis in coronary artery bypass grafting patients. J Tehran Heart Cent. 2010;5:25-8

3. Fukuda I, Gomi S, Watanabe K, Seita J. Carotid and aortic screening for coronary artery bypass grafting. Ann Thorac Surg. 2000;70:2034-9.

4. Anastasiadis K, Karamitsos TD, Velissaris I, Makrygiannakis K, Kiskinis D. Preoperative screening and management of carotid artery disease in patients undergoing cardiac surgery. Perfusion. 2009;24:257-62.

5. Durand DJ, Perler BA, Roseborough GS, Grega MA, Borowicz LM Jr, Baumgartner WA, et al. Mandatory versus selective preoperative carotid screening: a retrospective analysis. Ann Thorac Surg. 2004;78:159-66; discussion 159-66.

6. Shirani S, Boroumand MA, Abbasi SH, Maghsoodi N, Shakiba M, Karimi A et al. Preoperative carotid artery screening in patients undergoing coronary artery bypass graft surgery. Arch Med Res. 2006;37:987-90.

7. Lee EJ, Choi KH, Ryu JS, Jeon SB, Lee SW, Park SW, et al. Stroke risk after coronary artery bypass graft surgery and extent of cerebral artery atherosclerosis. J Am Coll Cardiol. 2011;57:1811-8.

8. Hillis LD, Smith PK, Anderson JL, Bittl JA, Bridges CR, Byrne JG, et al 2011 ACCF/AHA Guideline for Coronary Artery Bypass Graft Surgery. A report of the American College of Cardiology Foundation/American Heart Association Task Force on Practice Guidelines. Developed in collaboration with the American Association for Thoracic Surgery, Society of Cardiovascular Anesthesiologists, and Society of Thoracic Surgeons. Executive summary. $J$ Am Coll Cardiol. 2011;58:2584-614.

9. The Society of Thoracic Surgeons. Five things physicians and patient should question. Choosing wisely. An initiative of the ABIM Foundation. Available at: http://www.choosingwisely.org/doctor-patient-lists/the-societyof-thoracic-surgeons/ Accessed September 4, 2013.

10. Naylor AR. Managing patients with symptomatic coronary and carotid artery disease. Perspect Vasc Surg Endovasc Ther. 2010;22:70-6.

11. Gerraty RP, Gates PC, Doyle JC. Carotid stenosis and perioperative stroke risk in symptomatic and asymptomatic patients undergoing vascular or coronary surgery. Stroke. 1993;24:1115-8.

12. Li Y, Walicki D, Mathiesen C, Jenny D, Li Q, Isayev Y, et al. Strokes after cardiac surgery and relationship to carotid stenosis. Arch Neurol. 2009;66:1091-6.

13. Ghosh J, Murray D, Khwaja N, Murphy MO, Walker MG. The influence of asymptomatic significant carotid disease on mortality and morbidity in patients undergoing coronary artery bypass surgery. Eur J Vasc Endovasc Surg. 2005; 29:88-90.

14. Prasad SM, Li S, Rankin JS, O’Brien SM, Gammie JS, Puskas JD, et al. Curren outcomes of simultaneous carotid endarterectomy and coronary artery bypass graft surgery in North America. World J Surg. 2010;34:2292-8.

15. Naylor AR. Does the risk of post-CABG stroke merit staged or synchronous reconstruction in patients with symptomatic or asymptomatic carotid disease? J Cardiovasc Surg (Torino). 2009;50:71-81.

16. Roach GW, Kanchuger M, Mangano CM, Newman M, Nussmeier N, Wolman R, et al. Adverse cerebral outcomes after coronary bypass surgery. Multicenter Study of Perioperative Ischemia Research Group and the Ischemia Research and Education Foundation Investigators. N Engl J Med. 1996;335: 1857-63.

17. Brown PP, Kugelmass AD, Cohen DJ, Reynolds MR, Culler SD, Dee AD, et al The frequency and cost of complications associated with coronary artery bypass grafting surgery: results from the United States Medicare program. Ann Thorac Surg. 2008;85:1980-6.

18. Frye RL, Kronmal R, Schaff HV, Myers WO, Gersh BJ. Stroke in coronary artery bypass graft surgery: an analysis of the CASS experience. The 
participants in the Coronary Artery Surgery Study. Int J Cardiol. 1992;36: 213-21.

19. McKhann GM, Grega MA, Borowicz LM Jr, Bechamps M, Selnes OA, Baumgartner WA, et al. Encephalopathy and stroke after coronary artery bypass grafting: incidence, consequences, and prediction. Arch Neurol. 2002;59: 1422-8.

20. Salazar JD, Wityk RJ, Grega MA, Borowicz LM, Doty JR, Petrofski JA, et al. Stroke after cardiac surgery: short- and long-term outcomes. Ann Thorac Surg. 2001;72. 1195-201; discussion 1201-2.

21. Borger MA, Ivanov J, Weisel RD, Rao V, Peniston CM. Stroke during coronary bypass surgery: principal role of cerebral macroemboli. Eur J Cardiothorac Surg. 2001;19:627-32.

22. Schoof J, Lubahn W, Baeumer M, Kross R, Wallesch CW, Kozian A, et al. Impaired cerebral autoregulation distal to carotid stenosis/occlusion is associated with increased risk of stroke at cardiac surgery with cardiopulmonary bypass. J Thorac Cardiovasc Surg. 2007;134:690-6.

23. Hise JH, Nipper ML, Schnitker JC. Stroke associated with coronary artery bypass surgery. AJNR Am J Neuroradiol. 1991;12:811-4.

24. Naylor AR, Mehta Z, Rothwell PM, Bell PR. Carotid artery disease and stroke during coronary artery bypass: a critical review of the literature. Eur J Vasc Endovasc Surg. 2002;23:283-94.

25. John R, Choudhri AF, Weinberg AD, Ting W, Rose EA, Smith CR, et al. Multicenter review of preoperative risk factors for stroke after coronary artery bypass grafting. Ann Thorac Surg. 2000;69:30-5; discussion 5-6.

26. Mickleborough LL, Walker PM, Takagi Y, Ohashi M, Ivanov J, Tamariz M. Risk factors for stroke in patients undergoing coronary artery bypass grafting. J Thorac Cardiovasc Surg. 1996;112:1250-8; discussion 8-9.

27. Lynn GM, Stefanko K, Reed JF III, Gee W, Nicholas G. Risk factors for stroke after coronary artery bypass. J Thorac Cardiovasc Surg. 1992;104: 1518-23.

28. Stamou SC, Hill PC, Dangas G, Pfister AJ, Boyce SW, Dullum MK, et al. Stroke after coronary artery bypass: incidence, predictors, and clinical outcome. Stroke. 2001;32:1508-13.

29. Blauth CI, Cosgrove DM, Webb BW, Ratliff NB, Boylan M, Piedmonte MR, et al. Atheroembolism from the ascending aorta. An emerging problem in cardiac surgery. J Thorac Cardiovasc Surg. 1992;103:1104-11; discussion $11-2$.

30. Roffi M, Ribichini F, Castriota F, Cremonesi A. Management of combined severe carotid and coronary artery disease. Curr Cardiol Rep. 2012;14: 125-34.

31. Reich DL, Bodian CA, Krol M, Kuroda M, Osinski T, Thys DM. Intraoperative hemodynamic predictors of mortality, stroke, and myocardial infarction after coronary artery bypass surgery. Anesth Analg. 1999;89: 814-22.

32. Tokuda Y, Song MH, Ueda Y, Usui A, Akita T, Yoneyama S, et al. Three-dimensional numerical simulation of blood flow in the aortic arch during cardiopulmonary bypass. Eur J Cardiothorac Surg. 2008:33:164-7.

33. Newman MF, Wolman R, Kanchuger M, Marschall K, Mora-Mangano C, Roach G, et al. Multicenter preoperative stroke risk index for patients undergoing coronary artery bypass graft surgery. Multicenter Study of Perioperative Ischemia (McSPI) Research Group. Circulation. 1996;94: II74-80.

34. Hogue CW Jr, Murphy SF, Schechtman KB, Davila-Roman VG. Risk factors for early or delayed stroke after cardiac surgery. Circulation. 1999;100: 642-7.

35. Filsoufi F, Rahmanian PB, Castillo JG, Bronster D, Adams DH. Incidence, topography, predictors and long-term survival after stroke in patients undergoing coronary artery bypass grafting. Ann Thorac Surg. 2008;85: 862-70.

36. Nishiyama K, Horiguchi M, Shizuta S, Doi T, Ehara N, Tanuguchi R, et al. Temporal pattern of strokes after on-pump and off-pump coronary artery bypass graft surgery. Ann Thorac Surg. 2009;87:1839-44.

37. D’Agostino RS, Svensson LG, Neumann DJ, Balkhy HH, Williamson WA, Shahian DM. Screening carotid ultrasonography and risk factors for stroke in coronary artery surgery patients. Ann Thorac Surg. 1996;62:1714-23.

38. Katz ES, Tunick PA, Rusinek H, Ribakove G, Spencer FC, Kronzon I. Protruding aortic atheromas predict stroke in elderly patients undergoing cardiopulmonary bypass: experience with intraoperative transesophageal echocardiography. J Am Coll Cardiol. 1992;20:70-7.

39. Borger MA. Preventing stroke during coronary bypass: are we focusing on the wrong culprit? J Card Surg. 2005;20:58-9.
40. Forbes TL, Ricco JB. Trans-Atlantic debate: is carotid artery disease responsible for perioperative strokes after coronary artery bypass surgery? Eur J Vasc Endovasc Surg. 2010;40:695.

41. Sonny A, Gornik HL, Yang D, Mascha EJ, Sessler DI. Lack of association between carotid artery stenosis and stroke or myocardial injury after noncardiac surgery in high-risk patients. Anesthesiology. 2014;121:922-9.

42. Redgrave JN, Lovett JK, Gallagher PJ, Rothwell PM. Histological assessment of 526 symptomatic carotid plaques in relation to the nature and timing of ischemic symptoms: the Oxford plaque study. Circulation. 2006;113:2320-8.

43. Michel JB, Virmani R, Arbustini E, Pasterkamp G. Intraplaque haemorrhages as the trigger of plaque vulnerability. Eur Heart J. 2011;32:1977-85. 85a, 85b, 85c.

44. Takaya N, Yuan C, Chu B, Saam T, Polissar NL, Jarvik GP, et al. Presence of intraplaque hemorrhage stimulates progression of carotid atherosclerotic plaques: a high-resolution magnetic resonance imaging study. Circulation. 2005; 111:2768-75.

45. Singh N, Moody AR, Gladstone DJ, Leung G, Ravikumar R, Zhan J, et al. Moderate carotid artery stenosis: MR imaging-depicted intraplaque hemorrhage predicts risk of cerebrovascular ischemic events in asymptomatic men. Radiology. 2009;252:502-8.

46. Turc G, Oppenheim C, Naggara O, Eker OF, Calvet D, Lacour JC, et al. Relationships between recent intraplaque hemorrhage and stroke risk factors in patients with carotid stenosis: the HIRISC study. Arterioscler Thromb Vasc Biol. 2012:32:492-9.

47. Cambria RP. The endovascular revolution stopped at the carotid bifurcation... or did it? J Vasc Surg. 2012;56:1748-60.

48. Jorgensen L, Torvik A. Ischaemic cerebrovascular diseases in an autopsy series. I. Prevalence, location and predisposing factors in verified thrombo-embolic occlusions, and their significance in the pathogenesis of cerebral infarction. $\mathrm{J} \mathrm{Neu}$ rol Sci. 1966;3:490-509.

49. Castaigne P, Lhermitte F, Gautier JC, Escourolle R, Derouesne C. Internal carotid artery occlusion. A study of 61 instances in 50 patients with post-mortem data. Brain. 1970;93:231-58.

50. Pessin MS, Hinton RC, Davis KR, Duncan GW, Roberson GH, Ackerman RH, et al. Mechanisms of acute carotid stroke. Ann Neurol. 1979;6:245-52.

51. Jayasooriya G, Thapar A, Shalhoub J, Davies AH. Silent cerebral events in asymptomatic carotid stenosis. J Vasc Surg. 2011;54:227-36.

52. Altaf N, Goode SD, Beech A, Gladman JR, Morgan PS, MacSweeney ST, et al. Plaque hemorrhage is a marker of thromboembolic activity in patients with symptomatic carotid disease. Radiology. 2011;258:538-45.

53. Takaya N, Yuan C, Chu B, Saam T, Underhill H, Cai J, et al. Association between carotid plaque characteristics and subsequent ischemic cerebrovascular events: a prospective assessment with MRI-initial results. Stroke. 2006;37:818-23.

54. Altaf N, Daniels L, Morgan PS, Auer D, MacSweeney ST, Moody AR, et al. Detection of intraplaque hemorrhage by magnetic resonance imaging in symptomatic patients with mild to moderate carotid stenosis predicts recurrent neurological events. J Vasc Surg. 2008;47:337-42.

55. Lusby RJ, Ferrell LD, Ehrenfeld WK, Stoney RJ, Wylie EJ. Carotid plaque hemorrhage. Its role in production of cerebral ischemia. Arch Surg. 1982; 117:1479-88.

56. Silvestrini M, Vernieri F, Pasqualetti P, Matteis M, Passarelli F, Troisi E, et al. Impaired cerebral vasoreactivity and risk of stroke in patients with asymptomatic carotid artery stenosis. Jama. 2000;283:2122-7.

57. Nicolaides AN, Kakkos SK, Kyriacou E, Griffin M, Sabetai M, Thomas DJ, et al. Asymptomatic internal carotid artery stenosis and cerebrovascular risk stratification. J Vasc Surg. 2010;52:1486-96.e1-5.

58. Grant EG, Benson CB, Moneta GL, Alexandrov AV, Baker JD, Bluth EI, et al. Carotid artery stenosis: gray-scale and Doppler US diagnosis-Society of Radiologists in Ultrasound Consensus Conference. Radiology. 2003;229:340-6.

59. Screening for carotid artery stenosis: U.S. Preventive Services Task Force recommendation statement. Ann Intern Med. 2007;147:854-9.

60. Nicolaides A, Sabetai M, Kakkos SK, Dhanjil S, Tegos T, Stevens JM, et al. The Asymptomatic Carotid Stenosis and Risk of Stroke (ACSRS) study. Aims and results of quality control. Int Angiol. 2003;22:263-72.

61. Nicolaides AN, Kakkos SK, Griffin M, Sabetai M, Dhanjil S, Tegos T, et al. Severity of asymptomatic carotid stenosis and risk of ipsilateral hemispheric ischaemic events: results from the ACSRS study. Eur J Vasc Endovasc Surg. 2005;30:275-84.

62. Jmor S, El-Atrozy T, Griffin M, Tegos T, Dhanjil S, Nicolaides A. Grading internal carotid artery stenosis using B-mode ultrasound (in vivo study). Eur J Vasc Endovasc Surg. 1999;18:315-22. 
63. Griffin M, Nicolaides A, Kyriacou E. Normalisation of ultrasonic images of atherosclerotic plaques and reproducibility of grey scale median using dedicated software. Int Angiol. 2007;26:372-7.

64. Elatrozy T, Nicolaides A, Tegos T, Zarka AZ, Griffin M, Sabetai M. The effect of B-mode ultrasonic image standardisation on the echodensity of symptomatic and asymptomatic carotid bifurcation plaques. Int Angiol. 1998;17:179-86.

65. Tegos TJ, Sabetai MM, Nicolaides AN, Pare G, Elatrozy TS, Dhanjil S, et al. Comparability of the ultrasonic tissue characteristics of carotid plaques. J Ultrasound Med. 2000;19:399-407.

66. Sabetai MM, Tegos TJ, Nicolaides AN, Dhanjil S, Pare GJ, Stevens JM. Reproducibility of computer-quantified carotid plaque echogenicity: can we overcome the subjectivity? Stroke. 2000;31:2189-96.

67. Geroulakos G, Ramaswami G, Nicolaides A, James K, Labropoulos N, Belcaro G, et al. Characterization of symptomatic and asymptomatic carotid plaques using high-resolution real-time ultrasonography. Br J Surg. 1993;80: 1274-7.

68. Nicolaides AN, Kakkos SK, Griffin M, Sabetai M, Dhanjil S, Thomas DJ, et al. Effect of image normalization on carotid plaque classification and the risk of ipsilateral hemispheric ischemic events: results from the asymptomatic carotid stenosis and risk of stroke study. Vascular. 2005;13:211-21.

69. Spence JD. Technology Insight: ultrasound measurement of carotid plaquepatient management, genetic research, and therapy evaluation. Nat Clin Pract Neurol. 2006;2:611-9.

70. Golledge J, Cuming R, Ellis M, Davies AH, Greenhalgh RM. Carotid plaque characteristics and presenting symptom. Br J Surg. 1997;84:1697-701.

71. Bassiouny HS, Sakaguchi Y, Mikucki SA, McKinsey JF, Piano G, Gewertz BL, et al. Juxtalumenal location of plaque necrosis and neoformation in symptomatic carotid stenosis. J Vasc Surg. 1997;26:585-94.

72. Griffin MB, Kyriacou E, Pattichis C, Bond D, Kakkos SK, Sabetai M, et al. Juxtaluminal hypoechoic area in ultrasonic images of carotid plaques and hemispheric symptoms. J Vasc Surg. 2010;52:69-76.

73. Pedro LM, Fernandes e Fernandes J, Pedro MM, Goncalves I, Dias NV, Fernandes e Fernandes R, et al. Ultrasonographic risk score of carotid plaques. Eur J Vasc Endovasc Surg. 2002;24:492-8.

74. Sztajzel R, Momjian-Mayor I, Comelli M, Momjian S. Correlation of cerebrovascular symptoms and microembolic signals with the stratified gray-scale median analysis and color mapping of the carotid plaque. Stroke. 2006;37:824-9.

75. Kakkos SK, Griffin MB, Nicolaides AN, Kyriacou E, Sabetai MM, Tegos T, et al. The size of juxtaluminal hypoechoic area in ultrasound images of asymptomatic carotid plaques predicts the occurrence of stroke. J Vasc Surg. 2013;57: 609-18.e1; discussion 17-8.

76. Berens ES, Kouchoukos NT, Murphy SF, Wareing TH. Preoperative carotid artery screening in elderly patients undergoing cardiac surgery. J Vasc Surg. 1992; 15:313-21; discussion 22-3.

77. Sheiman RG. Janne d'Othee B. Screening carotid sonography before elective coronary artery bypass graft surgery: who needs it. AJR Am J Roentgenol. 2007; 188:W475-9.

78. Salasidis GC, Latter DA, Steinmetz OK, Blair JF, Graham AM. Carotid artery duplex scanning in preoperative assessment for coronary artery revascularization: the association between peripheral vascular disease, carotid artery stenosis, and stroke. J Vasc Surg. 1995;21:154-60; discussion 61-2.

79. Kiernan TJ, Taqueti V, Crevensten G, Yan BP, Slovut DP, Jaff MR. Correlates of carotid stenosis in patients undergoing coronary artery bypass grafting-a case control study. Vasc Med. 2009;14:233-7.

80. Drohomirecka A, Koltowski L, Kwinecki P, Wronecki K, Cichon R. Risk factors for carotid artery disease in patients scheduled for coronary artery bypass grafting. Kardiol Pol. 2010;68:789-94.

81. Ansari S, Tan JY, Larcos GS, Paterson H. Low prevalence of significant carotid artery disease on ultrasound in patients proceeding to coronary artery bypass surgery. Intern Med J. 2011;41:658-61.

82. Cornily JC, Le Saux D, Vinsonneau U, Bezon E, Le Ven F, Le Gal G, et al. Assessment of carotid artery stenosis before coronary artery bypass surgery. Is it always necessary? Arch Cardiovasc Dis. 2011;104:77-83.

83. Venkatachalam S, Gray BH, Mukherjee D, Shishehbor MH. Contemporary management of concomitant carotid and coronary artery disease. Heart. 2011;97:175-80.

84. Venkatachalam S, Shishehbor MH. Management of carotid disease in patients undergoing coronary artery bypass surgery: is it time to change our approach? Curr Opin Cardiol. 2011;26:480-7.

85. Augoustides JG. Advances in the management of carotid artery disease: focus on recent evidence and guidelines. J Cardiothorac Vasc Anesth. 2012;26:166-71.
86. Halliday A, Mansfield A, Marro J, Peto C, Peto R, Potter J, et al. Prevention of disabling and fatal strokes by successful carotid endarterectomy in patients without recent neurological symptoms: randomised controlled trial. Lancet. 2004;363:1491-502.

87. Endarterectomy for asymptomatic carotid artery stenosis. Executive Committee for the Asymptomatic Carotid Atherosclerosis Study. JAMA. 1995;273:1421-8.

88. Knipp SC, Scherag A, Beyersdorf F, Cremer J, Diener HC, Haverich JA, et al. Randomized comparison of synchronous $\mathrm{CABG}$ and carotid endarterectomy vs. isolated $\mathrm{CABG}$ in patients with asymptomatic carotid stenosis: the CABACS trial. Int J Stroke. 2012; 7:354-60.

89. Shishehbor MH, Venkatachalam S, Sun Z, Rajeswaran J, Kapadia SR, Bajzer C, et al. A direct comparison of early and late outcomes with three approaches to carotid revascularization and open heart surgery. J Am Coll Cardiol. 2013;62: 1948-56.

90. Barbut D, Grassineau D, Lis E, Heier L, Hartman GS, Isom OW. Posterior distribution of infarcts in strokes related to cardiac operations. Ann Thorac Surg. 1998;65:1656-9.

91. Manabe S, Shimokawa T, Fukui T, Fumimoto KU, Ozawa N, Seki H, et al. Influence of carotid artery stenosis on stroke in patients undergoing offpump coronary artery bypass grafting. Eur J Cardiothorac Surg. 2008;34: 1005-8.

92. Baiou D, Karageorge A, Spyt T, Naylor AR. Patients undergoing cardiac surgery with asymptomatic unilateral carotid stenoses have a low risk of peri-operative stroke. Eur J Vasc Endovasc Surg. 2009;38:556-9.

93. Mahmoudi M, Hill PC, Xue Z, Torguson R, Ali G, Boyce SW, et al. Patients with severe asymptomatic carotid artery stenosis do not have a higher risk of stroke and mortality after coronary artery bypass surgery. Stroke. 2011;42: 2801-5.

94. Naylor AR, Bown MJ. Stroke after cardiac surgery and its association with asymptomatic carotid disease: an updated systematic review and meta-analysis. Eur J Vasc Endovasc Surg. 2011;41:607-24.

95. Naylor AR. Synchronous cardiac and carotid revascularisation: the devil is in the detail. Eur J Vasc Endovasc Surg. 2010;40:303-8.

96. Antithrombotic Trialists' Collaboration. Collaborative meta-analysis of randomised trials of antiplatelet therapy for prevention of death, myocardial infarction, and stroke in high risk patients. BMJ. 2002;324:71-86.

97. Murkin JM, Adams SJ, Novick RJ, Quantz M, Bainbridge D, Iglesias I, et al Monitoring brain oxygen saturation during coronary bypass surgery: a randomized, prospective study. Anesth Analg. 2007;104:51-8.

98. Gerriets T, Schwarz N, Sammer G, Baehr J, Stolz E, Kaps M, et al. Protecting the brain from gaseous and solid micro-emboli during coronary artery bypass grafting: a randomized controlled trial. Eur Heart J. 2010;31:360-8.

99. Whitaker DC, Stygall J, Newman SP. Neuroprotection during cardiac surgery: strategies to reduce cognitive decline. Perfusion. 2002;17(Suppl):69-75.

100. Brott TG, Halperin JL, Abbara S, Bacharach JM, Barr JD, Bush RL, et al. 2011 ASA/ACCF/AHA/AANN/AANS/ACR/ASNR/CNS/SAIP/SCAI/SIR/SNIS/ SVM/SVS guideline on the management of patients with extracranial carotid and vertebral artery disease: executive summary: a report of the American College of Cardiology Foundation/American Heart Association Task Force on Practice Guidelines, and the American Stroke Association, American Association of Neuroscience Nurses, American Association of Neurological Surgeons, American College of Radiology, American Society of Neuroradiology, Congress of Neurological Surgeons, Society of Atherosclerosis Imaging and Prevention, Society for Cardiovascular Angiography and Interventions, Society of Interventional Radiology, Society of NeuroInterventional Surgery, Society for Vascular Medicine, and Society for Vascular Surgery. J Am Coll Cardiol. 2011;57:1002-44

101. Mohler ER III, Gornik HL, Gerhard-Herman M, Misra S, Olin JW, Zierler RE, et al. ACCF/ACR/AIUM/ASE/ASN/ICAVL/SCAI/SCCT/SIR/SVM/SVS/SVU [corrected] 2012 appropriate use criteria for peripheral vascular ultrasound and physiological testing part I: arterial ultrasound and physiological testing: a report of the American College of Cardiology Foundation appropriate use criteria task force, American College of Radiology, American Institute of Ultrasound in Medicine, American Society of Echocardiography, American Society of Nephrology, Intersocietal Commission for the Accreditation of Vascular Laboratories, Society for Cardiovascular Angiography and Interventions, Society of Cardiovascular Computed Tomography, Society for Interventional Radiology, Society for Vascular Medicine, Society for Vascular Surgery, [corrected] and Society for Vascular Ultrasound. [corrected]. J Am Coll Cardiol. 2012;60:242-76.

102. Qureshi AI, Alexandrov AV, Tegeler CH, Hobson RW II, Dennis Baker J, Hopkins LN. Guidelines for screening of extracranial carotid artery disease: a 
statement for healthcare professionals from the multidisciplinary practice guidelines committee of the American Society of Neuroimaging; cosponsored by the Society of Vascular and Interventional Neurology. J Neuroimaging. 2007; 17:19-47.

103. Komorovsky R, Desideri A. Carotid ultrasound assessment of patients with coronary artery disease: a useful index for risk stratification. Vasc Health Risk Manag. 2005;1:131-6.
104. Wanamaker KM, Moraca RJ, Nitzberg D, Magovern GJ Jr. Contemporary inci dence and risk factors for carotid artery disease in patients referred for coronary artery bypass surgery. J Cardiothorac Surg. 2012;7:78.

Key Words: carotid stenosis screening, stroke, coronary artery bypass grafting 